(NASA-CR-199624)

(NIPS-95-0.5494) DELTA WING VORTEX

N96-13159

MANIPULATION USING PULSED AND

STEADY BLOWING DURING RAMP PITCHING

, (worcester Polytechnic Inst.) $11 \mathrm{p}$

Unclas

$63 / 020072785$ 


\section{DELTA WING VORTEX MANIPULATION USING PULSED AND STEADY BLOWING DURING RAMP PITĊHING}

\author{
J. Moreira* and H. Johari ${ }^{\dagger}$ \\ Mechanical Engineering Department \\ Worcester Polytechnic Institute \\ Worcester, MA 01609
}
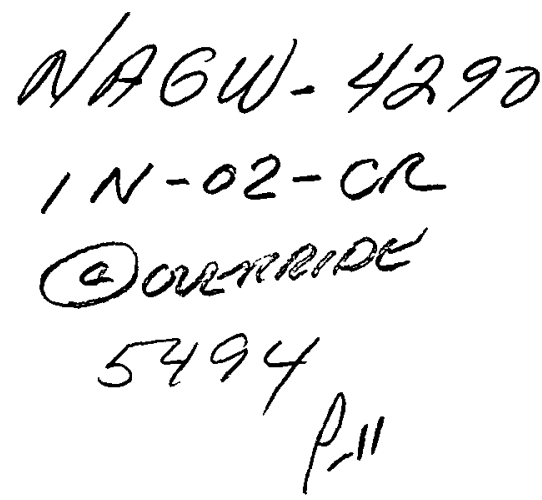

\begin{abstract}
The effectiveness of steady and pulsed blowing as a method of controlling delta wing vortices during ramp pitching has been investigated in flow visualization experiments conducted in a water tunnel. The recessed angled spanwise blowing technique was utilized for vortex manipulation. This technique was implemented on a beveled $60^{\circ}$ delta wing using a pair of blowing ports located beneath the vortex core at $40 \%$ chord. The flow was injected primarily in the spanwise direction but was also composed of a component normal to the wing surface. The location of vortex burst was measured as a function of blowing intensity and pulsing frequency under static conditions, and the optimum blowing case was applied at three different wing pitching rates. Experimental results have shown that, when the burst location is upstream of the blowing port, pulsed blowing delays vortex breakdown in static and dynamic cases. Dynamic tests verified the existence of a hysteresis effect and demonstrated the improvements offered by pulsed blowing over both steady blowing and no-blowing scenarios. The application of blowing, at the optimum pulsing frequency, made the vortex breakdown location comparable in static and ramp pitch-up conditions.
\end{abstract}

\section{Nomenclature}

$\begin{array}{ll}\mathrm{c} & \text { root chord length } \\ \mathrm{C}_{\mu} & \text { blowing coefficient }=\dot{\mathrm{m}}_{\mathrm{j}} \mathrm{V}_{\mathrm{j}} / \mathrm{q} \mathrm{S} \\ \mathrm{f} & \text { blowing frequency }(\mathrm{Hz}) \\ \mathrm{F} & \text { reduced blowing frequency }=2 \pi \mathrm{fc} / \mathrm{U}_{\infty} \\ \mathrm{K} & \text { normalized pitch rate }=\dot{\alpha} \mathrm{c} / \mathrm{U}_{\infty} \\ \dot{\mathrm{m}}_{\mathrm{j}} & \text { blowing fluid mass flow rate } \\ \mathrm{q} & \text { free stream dynamic pressure } \\ \mathrm{Re} & \text { Reynolds number, } \mathrm{U}_{\infty} \mathrm{c} / \mathrm{v} \\ \mathrm{S} & \text { wing planform area } \\ \mathrm{U}_{\infty} & \text { free stream velocity } \\ \mathrm{V}_{\mathrm{j}} & \text { mean blowing fluid velocity } \\ \mathrm{X} & \text { chordwise burst location } \\ \alpha & \text { angle of attack } \\ \dot{\alpha} & \text { pitch rate } \\ \mathrm{V} & \text { kinematic viscosity }\end{array}$

\footnotetext{
* Graduate student, member AIAA

†Assistant Professor, member AIAA
}

Copyright $(9) 1995$ by J. Moreira and H. Johari. Published by the American Institute of Aeronautics and Astronautics, Inc. with permission.

\section{Introduction}

The flow pattern about delta wings is distinguished by two primary vortices which provide a large portion of lift at high angles of attack. A delta wing's triangular planform causes free stream flow to separate at the leading edges, thereby forming shear layers. Through delicate flow visualization, Gad-elHak and Blackwelder ${ }^{1}$ showed that the leading edge shear layers consist of a series of discrete vortices in a fashion analogous to that of conventional planar shear layers. $^{2,3}$ These small discrete vortices in turn combine to create the primary vortices.

Discrete vortices were found to form at a specific frequency which is dependent upon free stream velocity as well as angle of attack. ${ }^{1}$ Although Gad-el-Hak and Blackwelder ${ }^{1}$ and Lowson ${ }^{4}$ both reported a single shedding frequency along the leading edges, recent numerical simulations of Gordnier and Visbal ${ }^{5}$ revealed that the shedding frequency of discrete vortices 
decreases at larger chordwise locations. Discrete vortices have been manipulated by perturbations at subharmonic frequencies in planar free shear layers. ${ }^{6}$ It was therefore postulated that the shedding frequency could be coupled with a perturbation to alter the primary vortex characteristics.

At high angles of attack, the primary vortices tend to break down or "burst;" this phenomenon is characterized by the abrupt expansion of the vortex core and the rapid reduction of axial velocity. Vortex breakdown reduces the lift created by the primary vortices, and the lift coefficient is strongly correlated with the chordwise location of breakdown. In order to control vortex breakdown on delta wings, a number of steady blowing techniques have been explored in the past. Conversely, relatively few investigations of unsteady blowing have been pursued. Inspired by the regular shedding of discrete vortices at the leading edge of delta wings, Gad-el-Hak and Blackwelder? experimented with pulsatile injection along the leading edges and found that the vortex core can be altered significantly when the perturbation frequency is a subharmonic of the natural shedding frequency. The injection velocity investigated was on the order of the free stream velocity. Vortex breakdown location as a function of frequency and amplitude of perturbation has been recorded by Shi et al. ${ }^{8}$ and Gu et al. ${ }^{9}$ on delta wings and by Vakili et al. ${ }^{10}$ in circular tubes. Meyer and Seginer ${ }^{11}$ investigated the effects of periodic spanwise blowing on the lift and drag of a fighter model with a $60^{\circ}$ sweep angle. At low frequencies, the vortex response generally lags behind the forcing by one convective time scale.

With the recent emphasis on the enhancement of fighter aircraft maneuverability, especially during transient motions, behavior of delta wing vortices under various dynamic conditions have been investigated. Both sinusoidal ${ }^{12-14}$ and ramp pitching ${ }^{15-17}$ motions have resulted in hysteretic location of the primary vortex breakdown and a nearly constant speed of breakdown location. The governing parameter for wings under dynamic conditions is the reduced frequency (sinusoidal) or the normalized pitch rate (ramp pitching). Although blowing techniques have been utilized to alter the vortex breakdown location on stationary wings, these techniques have not been used on delta wings experiencing transient pitching motions.

In the present effort, the effectiveness of steady and pulsed blowing as a method of delaying vortex breakdown on pitching delta wings has been investigated. The blowing configuration employed was the recessed angled spanwise blowing technique of Fitzpatrick et al. ${ }^{18}$ and is further explained in the next section. A $60^{\circ}$ delta wing was pitched up at a constant rate from stationary conditions at an $18^{\circ}$ angle of attack to $32^{\circ}$ and was then pitched down to create a saw-tooth pitching function. Only the first cycle of saw-tooth was studied since this case might realistically represent the pitching of a delta wing in practice, i.e. rapid pitch-up directly followed by pitch-down. Vortex breakdown location as a function of pitching rate, blowing coefficient, and pulsing frequency was measured by means of flow visualization.

\section{Apparatus}

The experiments were conducted in a free-surface water tunnel with a $60 \times 60 \mathrm{~cm}$ test section at a free stream velocity of $33.5 \mathrm{~cm} / \mathrm{sec}$. The test stand apparatus consisted of a delta wing, a pitching mechanism, and a blowing fluid delivery system. A $60^{\circ}$. delta wing with a $25^{\circ}$ leading edge bevel, previously used by Fitzpatrick et al. ${ }^{18}$, was modified for the present experiments. The bevel angle, which served to fix the separation point of the discrete vortices, was chosen to match the detailed study of O'Neil et al. ${ }^{19}$ The wing, which is depicted in Figure 1 , had a $25.7 \mathrm{~cm}$ root chord length, $30 \mathrm{~cm}$ trailing edge snan, and $1.9 \mathrm{~cm}$ thickness which resuited in a thickness-to-chord ratio of $7.4 \%$. In the absence of blowing, the wing sweep angle created vortices which burst between the trailing edge and vertex for $\alpha$ between $14^{\circ}$ and $34^{\circ}$. For this range, the solid blockage ratio of the water tunnel varied between $2.6 \%$ and $6 \%$. The Reynolds number based on the root chord length of the wing and the free stream velocity of the tunnel was $8.6 \times 10^{4}$.

Recessed Angled Spanwise Blowing (RASB), which was first studied by Fitzpatrick et al., ${ }^{18}$ uses ports on the delta wing planform to inject fluid in the spanwise direction and at an angle parallel to the leading edge bevel as shown in Figure 2. On the wing used in this study, a pair of $0.3 \mathrm{~cm}$ diameter ports were situated beneath the vortex axis at the $40 \%$ chord line of the wing, for this position yielded the most significant improvement in burst location during previous tests. ${ }^{18}$ Blowing at angles of attack for which

2 .

American Institute of Aeronautics and Astronautics 
the natural burst point was downstream of the port degraded the performance of the wing, and blowing from ports downstream of the natural burst point proved to be effective in delaying breakdown. It has been shown that the burst point at any given angle of attack is oscillatory in nature, and RASB appeared to reduce the frequency of this oscillation. 18,20

The fluid delivery system was designed to provide both steady and pulsed flow for blowing. The customary definition of blowing coefficient $\mathrm{C}_{\mu}$ (= $\dot{\mathrm{m}}_{\mathrm{j}} \mathrm{V}_{\mathrm{j}} / \mathrm{q} \mathrm{S}$ ) was used to nondimensionalize the blowing flow rate from a single port. According to earlier RASB studies ${ }^{18,20}$, any $C_{\mu}$ values greater than 0.03 would yield little further improvement in vortex burst location; it is noteworthy that the blowing coefficient in references 18 and 20 was defined for a pair of blowing ports. Since all tubing necessary for both blowing fluid and dye was housed internally in the wing, the thickness-to-chord ratio $(7.4 \%)$ was therefore uncharacteristically high. This may have imparted pseudo-conical flow characteristics near the apex which could potentially limit data accuracy. ${ }^{18}$

To control the blowing fluid flow, a 1/4" needle valve was used for adjusting the flow rate, and a 1/4", two-way, normally open solenoid valve enabled the system to create pulsatile flow. The fluid delivery system was capable of delivering enough fluid to achieve a $C_{\mu}$ of 0.1 given the wing geometry and test conditions. A square wave function generator was used for the pulsing, the frequency of which was normalized by the root chord length and the free stream velocity following Ref. 11. The reduced blowing frequency $F$ is therefore equal to $2 \pi \mathrm{fc} / \mathrm{U}_{\infty}$, where $\mathrm{f}$ is the frequency supplied by the wave generator $(\mathrm{Hz})$. In the present setup, reduced blowing frequencies could be varied within the range of 4.8 to 72.1 ; this corresponds to 1 to $15 \mathrm{~Hz}$. A duty cycle of 0.5 was chosen so that the valve would be open for the first half of the cycle and closed for the last half (systematic variations of duty cycle were not investigated in the present study). The fluid delivery system was run at a variety of settings, and the volume of blowing fluid delivered over a given time period was measured to determine the mean flow rate and blowing coefficient during pulsing operation. For pulsed blowing, all $\mathrm{C}_{\mu}$ values are averages over the time during which the valve is open, i.e., the timeaveraged blowing coefficient would be half as much as the steady blowing coefficient. The uncertainty in mean blowing coefficient is estimated to be about \pm 0.005 due primarily to flowmeter readability.

The pitching mechanism depicted in Figure 3 rotated the wing about its quarter-chord line. It consisted primarily of a six-bar linkage which was based loosely upon a similar one used by Miau et al. ${ }^{17}$

The pitching rate $\dot{\alpha}$ was nondimensionalized by the free stream velocity and the root chord. The pitching mechanism, whose other major components included the linkage's support frame, its motor, the motor control board, a gearbox, and a driving program, was designed to have minimal effect on the flow field about the wing and to maintain the tight tolerances necessary for accurate wing alignment. To avoid linkage-induced flow disruptions, all vertical bars were chamfered and placed at a distance of more than $30 \mathrm{~cm}$ aft of the delta wing's trailing edge.

An AC stepping motor was used to drive the mechanism because of both the ease with which it can change pitching rates and its nearly instantaneous start and stop control capabilities. A computer program which controlled the driving board (and therefore the pitching rate) was written and installed on a PC. The normalized pitch rate $(\mathrm{K})$ values were accurate to within $\pm 2.5 \%$ based upon the performance of the entire pitching mechanism, and the uncertainty in angle of attack measurements is on the order of $\pm 0.5^{\circ}$.

Vortex burst locations were obtained through flow visualization. Black dye was injected into the free stream from near the wing vertex, and all tests were recorded with a video camera. The wing was placed in the water tunnel with its planform facing the transparent floor of the test section to avoid any complications due to the tunnel's free surface. The planform image was captured by reflecting it towards the camera with a mirror which was placed on an angleadjustable stand to minimize parallax corrections.

The magnitude of primary vortex burst point oscillation was visually estimated at $\pm 2.5 \%$ of chord, and the average position was therefore used for all recording and analysis. Error margin in reading burst location was coincidentally estimated at $\pm 2.5 \%$ of chord due to the spacing of chord measurement lines on the wing. 


\section{$\underline{\text { Results }}$}

The test series conducted were separated into two phases: static and ramp pitching. Each phase included no-blowing, steady blowing, and pulsed blowing runs.

\section{Static Testing}

Initially, a series of baseline runs were performed for verification of experimental methods. The mean vortex breakdown location was measured with and without blowing for angles of attack greater than $14^{\circ}$; a well-defined vortex breakdown was not present below this angle. The static test results without blowing are presented in Fig. 4. The present vortex burst location data is compared with that of Fitzpatrick et al., 18 O'Neil et al., ${ }^{19}$ and Erickson. ${ }^{21}$ Except for $\alpha=14^{\circ}$ and $22^{\circ}$, the data agree within experimental uncertainty to the wind tunnel measurements of O'Neil et al. ${ }^{19}$ The data of Fitzpatrick et al. ${ }^{20}$ is also close until $22^{\circ}$, beyond which the present data is in agreement with the two other studies. Below $\alpha=26^{\circ}$ the data in Ref. 21 is consistently higher than others.

As expected, the application of steady blowing improved the vortex stability only when the natural burst location was upstream of the blowing port. At angles of attack for which the natural burst location was downstream of the blowing port $\left(\alpha \leq 18^{\circ}\right)$, the vortex not only burst close to the blowing port, but it had a tendency to swerve around the inside of the port. The diamster of the vortices, as indicated by the dye stream, decreased ncticeably during bluwing. Only blowing coefficients up to 0.03 were investigated since little further improvement was expected beyond this value, and, more importantly, this value may be the limit in practical applications. Once the natural burst point moved upstream of the port and closer to the apex, bursting was delayed by as much as $11 \%$ of root chord for the highest blowing coefficient at $22^{\circ}$. The results of steady blowing at $C_{\mu}=0.02$ and 0.03 are compared with the no-blowing data in Fig. 5(a).

Having discerned a noticeable difference between the effects of various blowing coefficients, $\mathrm{C}_{\mu}$ of 0.03 was used for all pulsed blowing runs. The reduced blowing frequency $\mathrm{F}$ was varied over the entire range of 4.8 to 72.1 ( 1 to $15 \mathrm{~Hz}$ ). The effect of pulsed blowing on the vortices proved to be more beneficial than that of steady blowing. When the natural burst point was located downstream of the port during pulsed blowing, the vortex broke down earlier than in the noblowing case and had the same tendency to curve around the port. Once the natural burst point moved upstream of the port and closer to the wing apex, vortex breakdown was delayed by as much as $20 \%$ chord at $\alpha$ $=24^{\circ}$ and $F=24$ as compared to no-blowing conditions. Vortex breakdown location as a function of $\alpha$ is shown in Fig. 5(b) for three different reduced blowing frequencies: $4.8,24$, and 48 . The most beneficial results occurred at a value of $F=24(5 \mathrm{~Hz})$. It was stipulated that this frequency was a source of improvement over steady blowing because it was a fundamental or sub-harmonic of the shedding frequency of the discrete vortices.

Reduced blowing frequencies of 48 and beyond resulted in negligible improvement over steady blowing across the $\alpha$ range of interest. The lowest reduced frequency was comparable with the optimum value of $F$ $=24$ up to $\alpha=24^{\circ}$. Beyond this angle, the burst location for $F=4.8$ edged closer to the steady blowing data. Fig. 5(c) is a plot of the burst locations for the most beneficial pulsed blowing, steady blowing, and no-blowing conditions. The data of Fitzpatrick et al. ${ }^{20}$ for steady blowing is also included in the plot for comparison. Below $\alpha=26^{\circ}$ the present steady blowing data agree with that in Ref. 20. Beyond this angle of attack, the burst location data of Ref. 20 fall below the present data. This is thought to be due to the significant difference between present baseline data and that of Ref. 20 as illustrated in Fig. 4. The angle of attack at which the breakdown reached the wing apex was increased by $4^{\circ}$ in the pulsed blowing and by $2^{\circ}$ in the steady blowing versus the no-blowing condition. Based on the static results, all dynamic testing was conducted with blowing at $C_{\mu}=0.03$ and pulsing at $F=24$, for these parameters produced the maximum improvement in vortex burst location in static runs.

\section{Dynamic Testing}

Dynamic tests were designed to determine the effects of steady and pulsed blowing on the vortex breakdown location above a pitching delta wing. $\mathrm{K}$ values were selected as $0.013,0.040$, and 0.067 ; these correspond to pitch rates of $1^{\circ}, 3^{\circ}$, and $5^{\circ}$ per second. All dynamic test data was drawn from the first cycle of ramp pitching motion from $\alpha=18^{\circ}$ to $32^{\circ}$ and back again to $18^{\circ}$. Initially, a series of baseline runs were conducted to compare the vortex breakdown 
characteristics with previous studies. The burst location for the normalized pitch rate of 0.067 as a function of $\alpha$ is contrasted against the static case in Fig. 6. As expected, a hysteresis or dynamic lag was observed for this as well as the other pitch rates. During pitch-up, vortex breakdown was delayed; and during pitch-down, vortex reformation was delayed. The present data is in qualitative agreement with the data in Ref. 17 since the wing thickness and Reynolds number in that study were about an order of magnitude smaller than the present values. At the start of pitch-up $\left(\alpha=18^{\circ}\right)$, the static and dynamic burst locations are in slight disagreement; this is attributed to experimental uncertainty and burst location oscillations.

Once the pitching technique was validated, two sets of dynamic tests were performed. In the first, blowing parameters were fixed and pitching rates were varied, and in the second, pitching rates were fixed and blowing parameters were varied.

The first series of tests compared the vortex burst location for normalized pitch rates of 0.04 and 0.067 under no-blowing, steady, and pulsed blowing conditions. Fig. 7(a) revealed that as the pitching rate increased, the magnitude of the hysteresis increased. Higher pitching rates also prevented the burst point from reaching the apex. The burst location, under static conditions, is near the apex at the highest $\alpha=32^{\circ}$. This effect was consistent through all dynamic runs. Hysteresis magnitude was such that there was a $0.10 \mathrm{c}$ difference in vortex breakdown location between $\mathrm{K}=$ 0.040 and $\mathrm{K}=0.067$ at $\alpha=32^{\circ}$, which was the peak of the ramp pitching motion. Fig. 7(b) shows that steady blowing delays vortex breakdown such that the slower pitching rate data begin to approach that of the faster pitch rate (i.e., steady blowing appears to reduce the delay in burst location at higher pitching rates). In fact, the burst location for the two pitch rates coincided at the peak of pitching motion. It can be seen in Fig. 7(c) that pulsed blowing nearly removed, to within experimental uncertainty, the difference in the burst location for the two pitch rates. Another interesting observation drawn from this data set is that there is a decrease in the burst location difference between the beginning and the end of the cycle as blowing is applied. The burst locations were identical for the two pitch rates at the start, the peak of pitch-up, and the final pitch-down $\alpha=22^{\circ}$.

The second series of tests depicted in Fig. 8, for which the pitching rates were held constant while blowing parameters were varied, showed that neither pulsed nor steady blowing reduced the magnitude of the hysteresis. Fig. 8(a) demonstrates the fairly consistent improvements offered over the entire angle of attack range by steady blowing over no-blowing and by pulsed blowing over steady blowing for the normalized pitch rate of 0.013 . Fig. 8(b) shows a similar trend for $\mathbf{K}=0.040$. It can also be seen that, during pitch-down, steady blowing proved to be more effective in reforming the vortex than pulsed blowing for $\alpha \geq 24^{\circ}$. At this pitch rate, pulsed blowing was more advantageous in this regard for $\alpha<21$. Pulsed blowing at $K=0.067$ caused the vortex breakdown to be further delayed over the no-blowing case across almost the entire $\alpha$ range, while steady blowing generally imposed less significant benefits as indicated by Fig. 8(c). During pitch-down, pulsed blowing was again shown to be only marginally effective for $\alpha<$ $24^{\circ}$. The reforming of the vortex near the end of the pitch-down period appears to be strongly affected by pulsed blowing at all three pitch rates and especially at the most rapid $\mathrm{K}=0.067$.

To compare the effects of blowing under static and dynamic conditions, Fig. 9 presents the previouslydisclosed data for $\mathrm{K}=0.067$ along with static data.

Steady-blowing dynamic burst location data is contrasted with static baseline and static blowing data in Fig. 9(A). It can be seen that the upstroke and downstroke of the ramp pitching motions straddle the static data, as expected. ${ }^{17}$ The vortex breakdown delay is smaller when the nitch-up data is compared with static steady blowing instead of the baseline data.

Steady blowing expands the difference between baseline cases to margins as great as $\pm 14 \%$ of chord at $\alpha=30^{\circ}$ (this trend is evident through most of the angle of attack range). In Fig. 9(b) it can be seen that pulsed blowing intertwines the data for the static case and the ramp pitching upstroke. The magnitude of improvement in vortex breakdown location under pulsed blowing conditions is such that the effects of pitch-up at $K=0.067$ cannot be distinguished from the static case. Moreover, vortex reformation during the downstroke is significantly facilitated by pulsed blowing; the burst location at $\alpha=22^{\circ}$ is almost at the same location as that for a stationary wing.

Questions arise as to the effect of increasing the pitch rates beyond the values tested in the present experiments. From previous findings, one would expect to observe a larger delay in vortex breakdown 
location (wider hysteresis loop) when blowing is absent. The application of blowing will probably yet be beneficial, albeit to a lesser degree. Both ramp pitch-up and blowing tests show delays of vortex breakdown despite their different effects on vortex stability. The issue then becomes determining which one will be able to exert a larger influence on the vortex. At the lower pitch rates in Fig. 7, both steady and pulsed blowing further extended the delay created by pitching alone. At $\mathrm{K}=0.067$, the effects of pulsed blowing over baseline pitching were only observable for $26^{\circ}<\alpha<30^{\circ}$. At large normalized pitch rates, the effects of blowing may be overshadowed by the pitching. However, the application of blowing can be quite advantageous during the pitch-down cycle since the vortex will be reformed much faster.

Another issue which needs to be addressed involves optimum blowing parameters when the wing is experiencing ramp pitching motions. In the present study, only the most beneficial blowing conditions in the static case were applied in the dynamic tests. It is possible to investigate whether larger blowing intensities would significantly alter the burst location in the ramp pitching runs. However, appreciably larger blowing intensities may not be feasible from a practical standpoint. Moreover, previous studies ${ }^{18,20}$ of the RASB method have shown that doubling the blowing coefficient for a stationary wing will not alter the burst location substantially. The pulsing frequency, on the other hand, is a function of the shedding frequency of discrete vortices at the leading edges. The shedding frequency in turn is dependent on both the Reynolds number and the angle of attack. ${ }^{1}$ For a $60^{\circ}$ delta wing, the reported shedding frequency in Ref. 1 varies only by about $14 \%$ over the range of pitching in these experiments. Therefore, unless the shedding frequency is strongly dependent upon the pitch rate, there should be a single optimum pulsing frequency for both static and dynamic cases. Further experiments are planned to address the dependence of optimum pulsing frequency on pitch rate.

\section{Conclusions}

Pulsed blowing is an effective means of delaying vortex breakdown when the blowing port is downstream of the natural burst point in the Recessed Angled Spanwise Blowing (RASB) configuration. Pulsing at the proper frequency (which is a function of the natural shedding frequency of the discrete vortices) was capable of enhancing the vortical flow over the delta wing and therefore delaying breakdown. The existence of a hysteresis effect during ramp pitching, the magnitude of which increased with increasing pitch rate, was verified. Pitching upward delayed vortex breakdown, and pitching downward delayed vortex reformation. Pulsed blowing was a consistent benefactor in delaying breakdown during ramp pitching, and it delayed breakdown to a greater extent than steady blowing in most cases. The application of pulsed blowing made vortex breakdown location comparable in static and ramp pitch-up conditions.

Furthermore, vortex reformation during the downstroke is significantly facilitated by pulsed blowing. The improvements offered by pulsed blowing warrant further testing on delta wings with other sweep angles, such as $70^{\circ}$. Higher pitch rates could be investigated as well, perhaps under more realistic conditions, i.e., using fighter models.

\section{Acknowledgments}

The help of undergraduate students Matthew Meyer, Michael Rhein, and Barry Rodrigues with the design and assembly of the experimental apparatus is gratefully acknowledged. The authors also. wish to thank Todd Billings for his tutelage in manufacturing many of the components of the pitching mechanism. J.M. was supported by NASA Grant NAGW.-4290. -

\section{References}

1. Gad-el-Hak, M., and Blackwelder, R., "The Discrete Vortices from a Delta Wing," AIAA Journal, Vol. 23, No. 6, 1985, pp. 961-962.

2. Brown, G.L., and Roshko, A., "On Density Effects "and Large Structure in Turbulent Mixing Layers," Journal of Fluid Mechanics, Vol. 64, 1974, pp. 775-816.

3. Winant, C.D., and Browand, F. K., "Vortex Pairing: The Mechanism of Turbulent Mixing Layer Growth at Moderate Reynolds Number," Journal of Fluid Mechanics, Vol. 63, 1974, pp. 237-255.

4. Lowson, M.V., "The Three Dimensional Vortex Sheet Structure on Delta Wings," Fluid Dynamics of Three-Dimensional Turbulent Shear Flows and Transition, AGARD-CP-438, Cesme, Turkey, October 1988, pp. 11.1-11.16. 
5. Gordnier, R.E., and Visbal, M.R., "Unsteady Vortex Structure over a Delta Wing," Journal of Aircraft, Vol. 31, No. 1, pp. 243-248.

6. Ho, C.-M. and Huerre, P., "Perturbed Free Shear Layers," Annual Review of Fluid Mechanics, Vol. 16,1984 , pp. 365-424.

7. Gad-el-Hak, M., and Blackwelder, R., "Control of the Discrete Vortices from a Delta Wing," AIAA Journal, Vol. 25, No. 8, 1987, pp. 1042-1049.

8. Shi, Z., Wu, J. M., and Vakili, A. D., "An Investigation of Leading-Edge Vortices on Delta Wings with Jet Blowing," AIAA Paper 87-0330, January 1987.

9. Gu, W., Robinson, O., and Rockwell, D., "Control of Vortices on a Delta Wing by Leading-Edge Injection," AIAA Journal, Vol. 31, No. 7, 1993, pp. 1177-1186.

10. Vakili, A. D., Eramo, R., and Tennent, S. B., "Increasing and Decreasing the Stability of a Confined Vortex by Forcing," AIAA Paper 933039, July 1993.

11. Meyer, J., and Seginer, A., "Effects of Periodic Spanwise Blowing on Delta Wing Configuration Characteristics," AIAA Journal, Vol. 32, No. 4, 1994, pp. 708-715.

12. Gad-el-Hak, M., and Ho, C.-M., "The Pitching Delta Wing," AIAA Journal, Vol. 23, No. 11, 1985, pp. 1660-1665.

13. LeMay, S. P., Batill, S. M., and Nelson, R. C., "Vortex Dynamics on a Pitching Delta Wing," Journal of Aircraft, Vol. 27, No. 2, 1990, pp. 131138.

14. Guglieri, G., Onorato, M., and Quagliotti, F., "Breakdown Analysis on Delta Wing Vortices," Zeitschrieft Flugwissen Weltraumforsch, Vol. 16, 1992, pp. 226-230.

15. Thompson, S.A., Batill, S.M., and Nelson, R.C., "The Separated Flowfield on a Slender Delta Wing Undergoing Transient Pitching Motions," Journal of Aircraft, Vol. 28, No. 8, 1991, pp. 489-495.

16. Magness, C., Robinson, O., and Rockwell, D., "Control of Leading-Edge Vortices on a Delta Wing," AIAA Paper 89-0999, March 1989.

17. Miau, J.J., Chang, R.C., Chou, J.H., and Lin, C.K., "Nonuniform Motion of Leading-Edge Vortex Breakdown on Ramp Pitching Delta Wings," AIAA Journal, Vol. 30, No. 7, 1992, pp. 1691-1702.

18. Johari, H., Olinger, D.J., and Fitzpatrick, K.C., "Delta Wing Vortex Control via Recessed Angled
Spanwise Blowing," Journal of Aircraft, (to appear).

19. O'Neil, P. J., Roos, F. W., Kegelman, R. M., Barnett, R. M., Hawk, J.D., "Investigation of Flow Characteristics of a Developed Vortex," NADC Report 89114-60, Warminster, PA, May 1989.

20. Fitzpatrick, K., Johari, H., and Olinger, D., "A Visual Study of Recessed Angled Spanwise Blowing Method on a Delta Wing," AIAA Paper 93-3246, July 1993.

21. Erickson, G.E., "Flow Studies of Slender wing Vortices," AIAA Paper 83-2114, 1983.

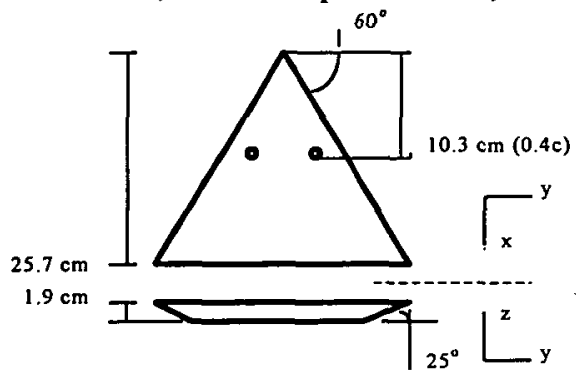

Figure 1: Delta wing dimensions and blowing port locations

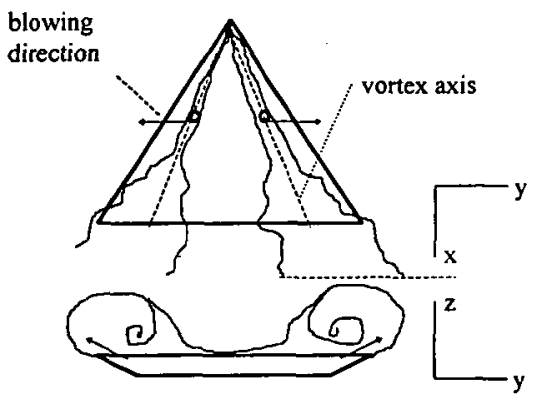

Figure 2: Schematic of recessed angled spanwise blowing

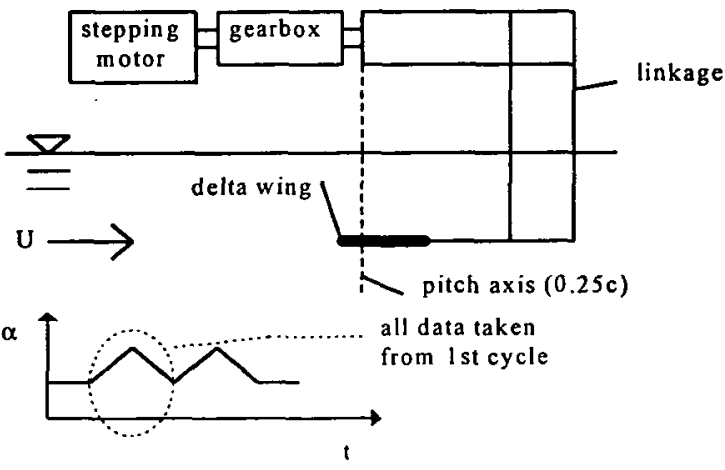

Figure 3: Pitching mechanism schematic 


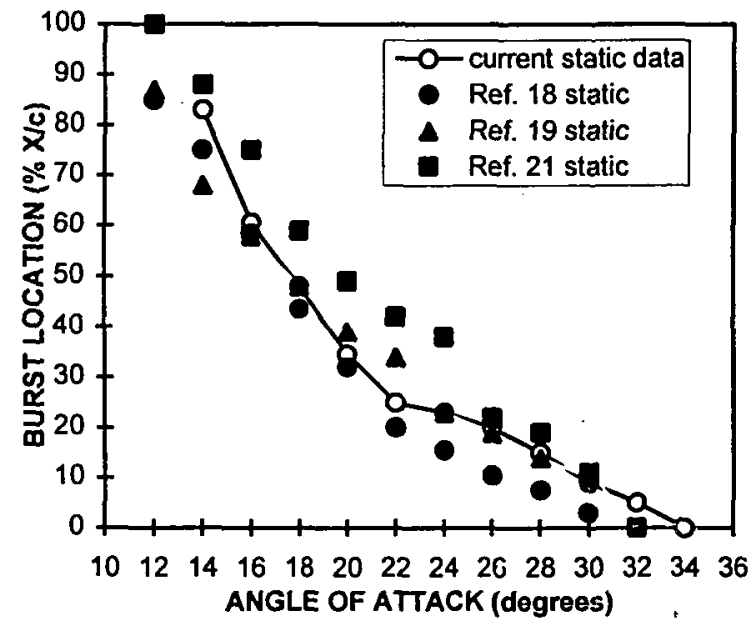

Figure 4: Baseline vortex burst location (no blowing); current data at $\operatorname{Re}=8.4 \times 10^{4}$
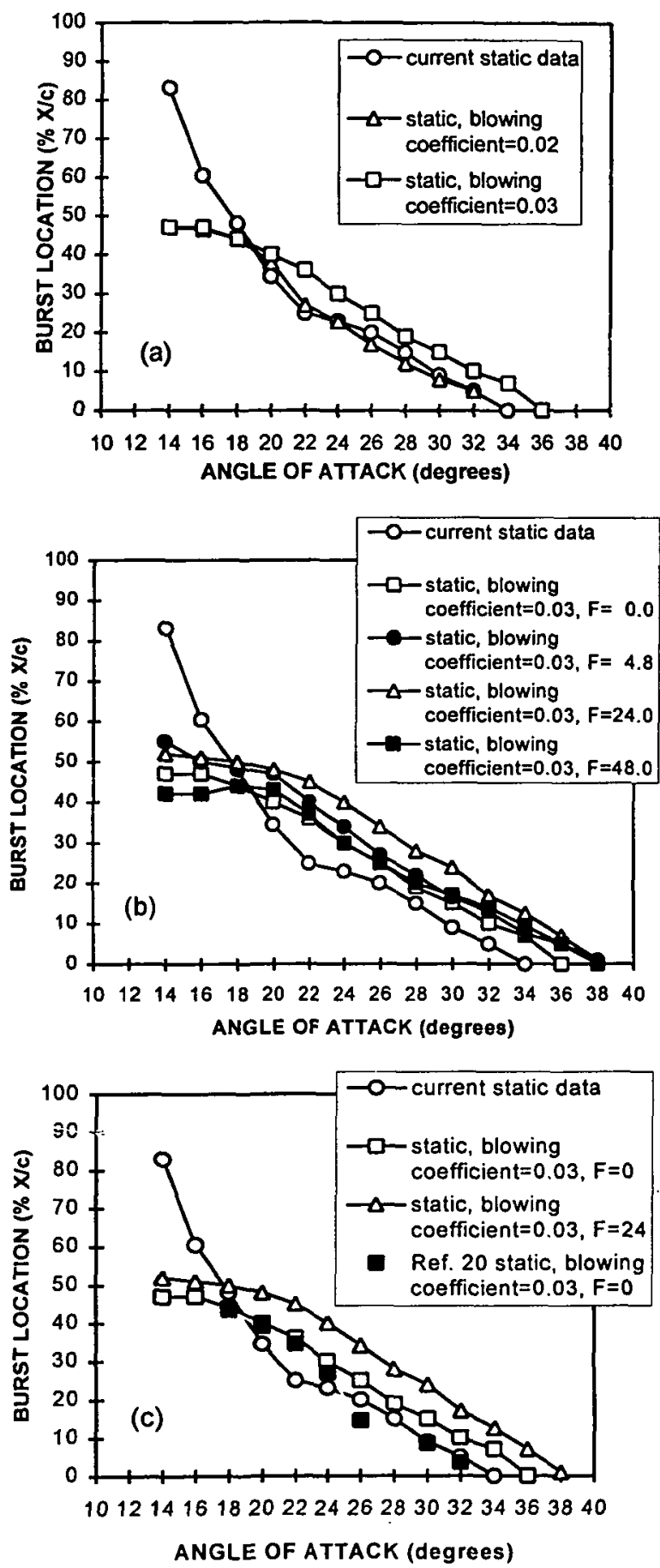

Figure 5: Burst location with various blowing configurations: (a) steady blowing with $C_{\mu}=0.02$ and 0.03 , (b) steady and pulsed blowing with $\mathrm{C}_{\mu}=0.03$, (c) best advantage blowing parameters

8

American Institute of Aeronautics and Astronautics 

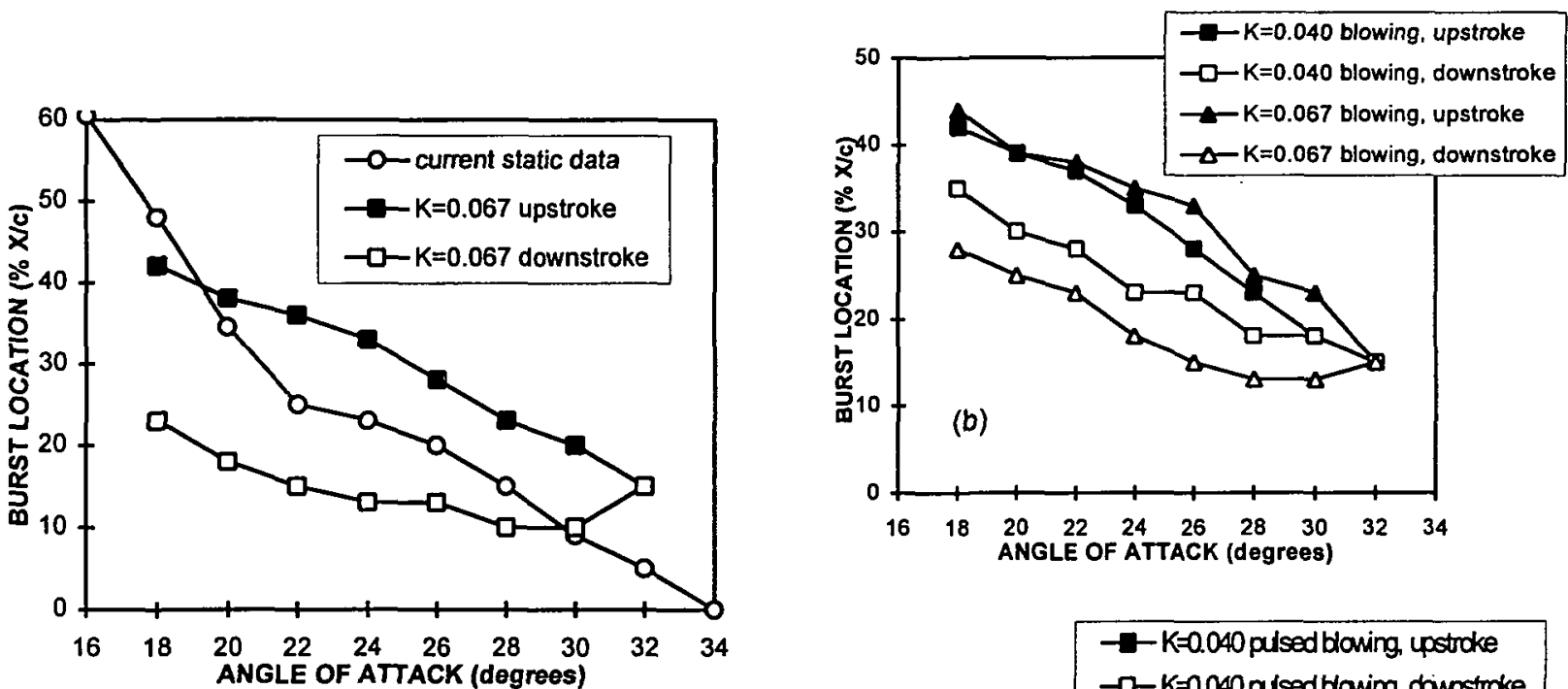

Figure 6: Baseline burst location during ramp pitching, $\mathrm{K}=0.067$ (no blowing)

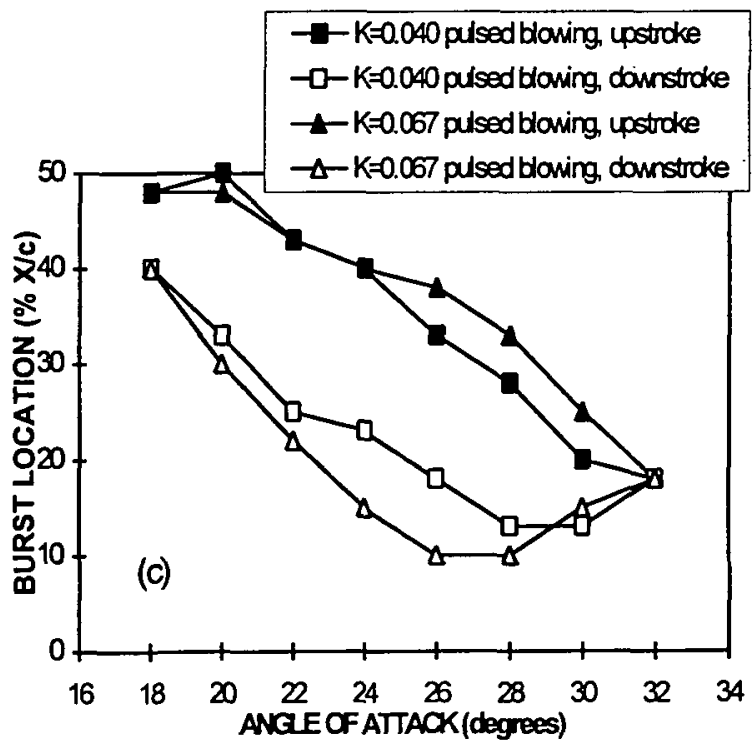

Figure 7: Burst location in ramp pitching: (a) no blowing, (b) steady blowing, $C_{\mu}=0.03$, (c) pulsed blowing, $C_{\mu}=0.03, F=24$

9.

American Institute of Aeronautics and Astronautics 

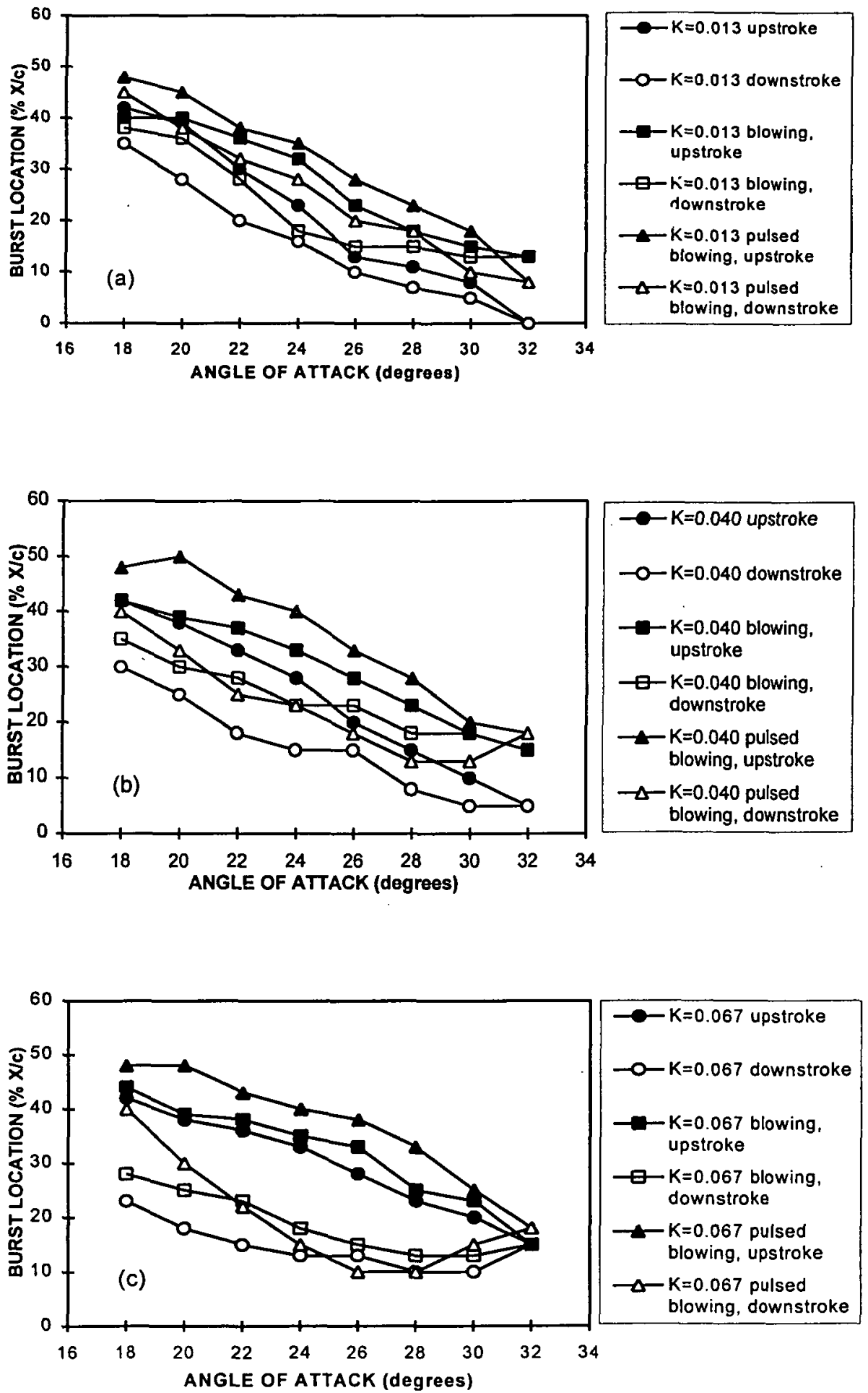

Figure 8: Burst location comparison for: (a) $K=0.013$, (b) $K=0.040$, (c) $K=0.067$

10

American Institute of Aeronautics and Astronautics 

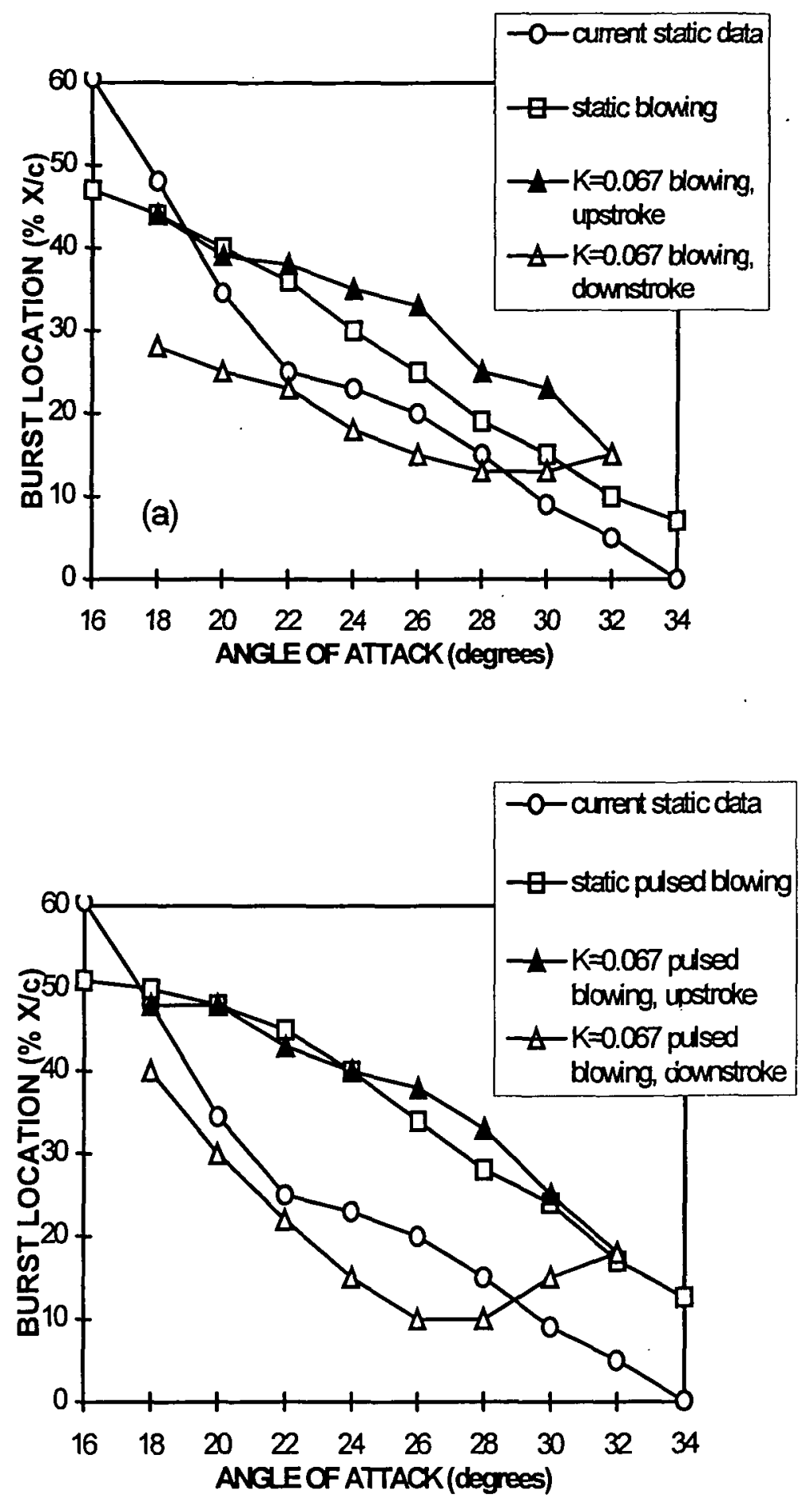

Figure 9: Comparison of satic and dynamic burst location with: (a) steady blowing, (b) pulsed blowing 11

American Institute of Aeronautics and Astronautics 